\title{
COMMUNITY-BASED TOURISM IN RURAL JAPAN: THE CASE OF A NETWORK-MAKING NON-PROFIT ORGANIZATION
}

\author{
YASUO OHE \\ Department of Food and Resource Economics, Chiba University, Japan
}

\begin{abstract}
This paper investigates community-based rural tourism development by focussing on the roles of a network-making non-profit organization (NPO) in Miyagi in northern Japan. The study took a case study approach in examining the Kurihara Tourism Network (KTN), which is an NPO engaging in rural tourism activity. First, we conceptually classified the types of community-based tourism. Second, the features of the KTN activities and what roles the KTN played were empirically clarified. Results revealed that KTN connects people in the local community through formulating original tourism programs by taking advantage of their authentic rural and food heritage. To realize their aim, firstly the KTN took a holistic approach in establishing tourism programs rather than a fragmentary approach, which has been popular among rural experience programs that provide only popular experience menus such as planting and harvesting. Secondly, the KTN mobilized dying heritage and skills embedded in the life of the local people, which easily enabled local residents to participate as instructors. Thus, these KTN policies created new social capital in the community and created a new network or recreated what used be in a modern way. Finally, the challenging issues that the KTN face are to raise financial viability and more efficient program management.
\end{abstract}

Keywords: community-based tourism, rural tourism, social capital, rural heritage, local food.

\section{INTRODUCTION}

Community-based tourism (CBT) development has been attracting growing attention in various parts of the world not only in developing countries, but also in developed countries [1]. Hatton [1] collected case studies from 12 different countries and areas in the Asian and Pacific regions. Manhas et al. [2] focussed on CBT case studies in India that included rural areas. Along with the rising interest in CBT, approaches to the study of CBT have also been diversified. Dittmann [3] addressed a township-tourism case by focussing on Cape Town in South Africa from a perspective of destination management. Burgos and Mertens [4] addressed management of CBT in Brazil from the point of view of a social network. Masud et al. [5] explored factors that influenced community participation in the sustainable development of community-based ecotourism in marine protected areas in Malaysia. Masud et al. [5] concluded that raising environmental knowledge is an important factor in community participation. Ernawati et al. [6] investigated the perceptions of host communities and tourists involved in CBT in Bali, Indonesia, and found that the host communities lacked the confidence to share the intrinsic values of tourist attractions with tourists. Another study in Bali examined the role of the governing village body in CBT in Bali [7]. Durkin and Perić [8] studied the organizational aspects of sustainable CBT development in Croatia and stated that it is important to design an efficient organizational structure in line with the interests and needs of local community stakeholders. Giampiccoli and Mtapuri [9] proposed a classification of CBT by incorporating five aspects: equity, education, empowerment, endogeny and the environment. Ohe and Kurihara [10] statistically verified a positive connection between local brand farm products and tourism in rural Japan. Ohe et al. [11] clarified the advantages and challenges of an emerging type of community-based forest therapy tourism in Japan. Cai et al. [12] dealt with issues of tourism branding in communities, 
which is an essential factor for the sustainable development of CBT. As a study on the demand side, Kim and Park [13] examined the relationships among perceived value, satisfaction and destination loyalty of tourists to community-based ecotourism villages in Korea by a structural equation model. In short, it can be said that these preceding studies did not pay enough attention to the roles of NPOs despite that essential roles of NPOs could be expected. This lack provides the rationale for this study.

Tourism in rural areas faces more severe resource constraints than its urban counterpart especially on human, financial and information resources due to the faster progression of an ageing population and depopulation than in urban areas. Ohe [14] shed light on the issues of an ageing rural community and CBT in Japan, which is the most advanced ageing society in the world. Nevertheless, that study did not focus on the roles of NPOs.

To counter these disadvantages, network-making NPOs are playing a vital role [15]. Nevertheless, little has been studied on the roles of NPOs in the development of rural tourism except by Ohe [15]. Ohe [15] pointed out the distinctive roles that NPOs have played but that other destination stakeholders were not able to perform proficiently such as program development, horizontally connecting people and training operators. Ohe [15], however, did not address how actual tourism programs are developed and implemented by NPOs. This aspect needs to be clarified to gain a more clearer vision of the roles of NPOs.

\section{METHODOLOGY}

Thus, this paper investigates what roles NPOs play in the development of rural tourism by focussing on one NPO designated as "the Kurihara Tourism Network" (KTN), which conducts rural tourism by creating a network among people in the local communities in Kurihara, northern Japan. The activity of this NPO has been highly evaluated and this NPO has received many awards in this country. The author believes that KTN provides us with important insights on what roles NPOs should play and the issues they face. One of the key concepts of CBT is social capital, which defines how CBT can be developed. Thus, first this paper presents conceptual types of CBT. Second, as a case study the characteristics of the KTN are investigated. Lastly, policy implications for CBT development in rural areas are presented.

\section{RESULTS}

\subsection{Conceptual model}

Firstly, this paper conceptually considers the types of CBT in rural areas. Fig. 1 illustrates three cases of CBT. Case 1 is the hamlet-based case that conducts CBT based on a traditional local community. The hamlet is the basic unit of life in rural Japan. The merit of this unit is that all members are well known to each other and that a strong bond among members exists. So, it is relatively easy to reach a consensus among people concerned because they have known each other well from childhood. Put differently, they have firm social capital. This social capital is a closed one often called the Colman type of social capital [16], [17]. Nevertheless, this closeness has a downside as well because it entails a less flexible and narrower resource availability than the wider range of social capital. Case 2 is CBT that is conducted within one municipality. In this case, the government of the municipality quite often takes the initiative. In other words, a strong initiative undertaken by a municipality is a precondition for this type of CBT. Although other bodies such as local community groups could take this role, it is most common that a municipality takes the initiative. Case 3 is that of a CBT performed across municipalities. In this case, network-making bodies such as NPOs 


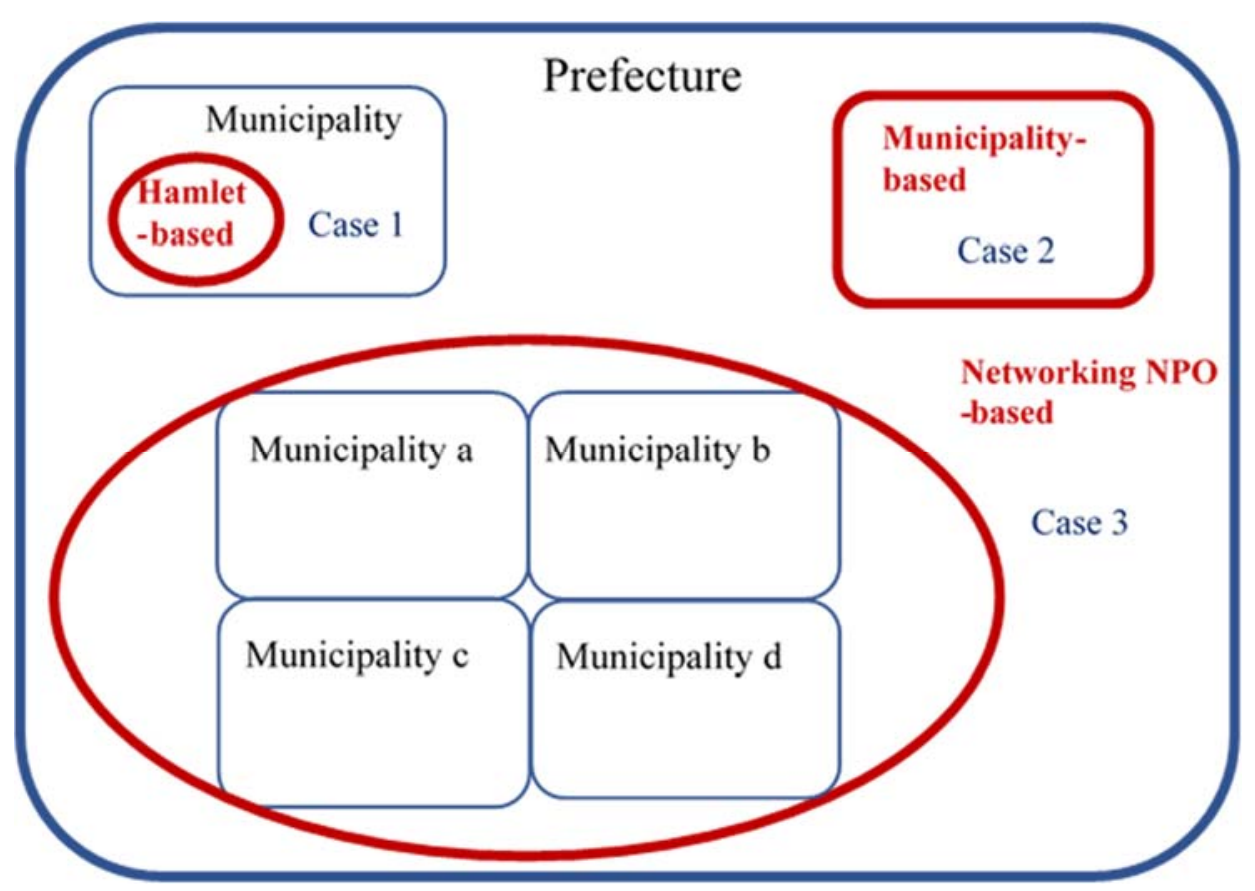

Figure 1: Types of CBT: conceptual understanding; various types of social capital.

are expected to play an important role because the single unit of a hamlet or municipality is not easily able to address this range of activity.

This is why NPOs are expected to play a role in this case that covers a wider range beyond the boundary of a single municipality or hamlet. The purpose of this paper is to explore the development of inter-municipality CBT, i.e. Case 3, so that it is rational to focus on the role of network- making NPOs.

\subsection{Case study}

\subsubsection{Study area: background of Kurihara}

The studied case, KNT, is located in the rural municipality, Kurihara, in the north of Miyagi Prefecture, northern Japan (for the characteristics of rural tourism in Japan, see [18]). The survey was conducted by the author and members of the Tohoku Regional Advancement Center and directed toward the secretary general of this NPO at the organization's office in Kurihara in August 2017. Survey method was an interview during which we asked the secretary general to explain the activities of the NPO. Miyagi prefecture is the most seriously damaged prefecture by the Great East Japan Earthquake in March 2011 in terms of the number of lives lost and devastated houses in the coastline areas. Nevertheless, Kurihara is located not near the coast but inland so that it suffered no serious physical damage. Kurihara is a relatively newly formed municipality as the result of the merger of 10 municipalities in April 2005. Mergers of municipalities have been promoted by the national government to promote more efficient administration of municipalities. The case of a merger of 10 municipalities, however, is not common because it is not so easy to reach consensus among many municipalities concerned. The population of Kurihara has been continuously 
decreasing, from 82,298 in 2005 to 70,792 in 2016, and ageing, so that the percentage of those who are 65 years and older rose from $30.1 \%$ to $36.3 \%$ during the same period. Like other rural areas in this country, ageing in this rural area has progressed far faster than the national average, which is already the highest percentage in the world, $27.3 \% 65$ years or older in 2016 [19]. In accordance with the population decrease, economic activity of agriculture and other industries has also been shrinking. Rice production is a major crop in this area. That is the background of Kurihara where this NPO is located.

\subsubsection{Study case: the Kurihara Tourism Network}

Now let me examine the aims, structure and activities of the KTN. The KTN was established in March 2010 and subsequently became an NPO in April 2016. It now has four fulltime staff members and a membership of 105 comprised of 78 individuals and 27 groups. These individuals have a wide range of occupations: farmers; operators of farm accommodations, farm restaurants, farm shop and hotel and restaurants; a carpenter; a guide; a tatami mat maker; a ceramicist; a Noh, i.e. traditional mask artist; another NPO, etc. Thus, it is safe to say that the KTN connects these people horizontally within the rural community. The main activities of the KTN are as follows: tourism, selling of goods, study of local resources, design services for flyers and brochures for local shops, training services for those in the local community and public relations. Tourism is the main activity of the KTN and it implements and manages rural experiences programs that were developed by the KTN. The KTN also hosts school educational trips, planning of tourism programs and hosts study tours about KTN's activities to share what KTN has experienced. The selling of goods is conducted by what has been named the "Jumonji store", which sells traditional handcrafted goods. The study of local resources is to discover forgotten local resources that might be useful for the development of CBT because the Tohoku region in which Kurihara is located has an abundant cultural heritage in the rural communities. The KTN provides contracted design services for flyers and brochures for local shop owners. Training program offers opportunities to local members to visit model practices in other parts of Japan and to organize courses to study together and exchange information. Public relations involve web-based activity through the KTN's own website and social media and also taking care of media coverage and publicity. All of these activities are performed by the four full-time staff members including the Secretary General, which keeps them busy.

The outcome of the activity of the KTN is summarized as follows: annual budget in 2016 was 20 million Yen (nearly 148 thousand Euro, as 1 Euro $=135$ Yen) and revenue was 17 million Yen from program-related activities and 3 million Yen from a subsidy by the municipality. Cost-wise, personnel costs account for the largest share, $60 \%$ or 12 million Yen, followed by program-related costs of 7.5 million Yen and management costs of 1.7 million Yen. The number of participants in 2015 in tourism and goods selling are shown in Table 1. Although those two major activities attracted about the same number of participants, the number of times that the activities took place differed between the two. This is because $\mathrm{KTN}$ tries to raise revenue per participant in tourism programs.

Table 1: KTN activity and outcome.

\begin{tabular}{ccc}
\hline Activity & No. participants & No. times \\
\hline Tourism & 2,064 & 135 \\
Goods selling & 1,964 & 19 \\
Total & 4,024 & 154 \\
\hline
\end{tabular}

Source: KTN as of the 2015 fiscal year. 
The KTN attaches importance to two things. First, local culinary and living heritage are respected because ordinary local people themselves are living examples of their heritage, and their daily jobs and hobbies can be easily utilized in authentic experience programs.

Second, the KTN is not oriented toward mass tourism, but toward small groups in tours with a short duration. This is to raise revenue per participant as stated above and to guarantee the authenticity of the experience program. The secretary of the KTN considers that authenticity is a crucial factor for tourism programs.

Although the KTN provides many programs, it is not possible to mention all of them due to the space limitation for this chapter. Thus, this paper focussed on only distinctive programs as mentioned below.

\subsubsection{Activity in practice: food-heritage experience programs}

The most popular programs are ones that are related to food heritage because the Kurihara region embraces an abundant food heritage. Let me describe what programs are practiced specifically. First, in line with food heritage-related programs, a traditional food, a steamed cake made from wheat flour that was customarily prepared as a treat for farmers during the break in farm work between meals, is prepared by the tourists. Nevertheless, this custom of refreshments for farmers was almost forgotten during the modernization process of farm operations. Commonly the cakes were served in a bamboo basket also crafted by local residents. The bamboo basket was also forgotten with the progress of modern living. Therefore, the KTN started a program that allows participants to experience both making the traditional treat and the bamboo basket as one set.

The second food experience program was tofu making using a local soybean variety and by using a traditional square wooden box called "masu" to contain it and a cotton cloth to cover it made by farmers. This involves a collaboration between a local carpenter who makes the masu and farmers who grew the soybeans and made the cotton cloth. Thus, what KTN looks at is not only food per se, but also the holistic food heritage. In line with this policy, the KTN implemented food experience programs based on the collaboration with local stakeholders, which connects people to people through this activity and eventually leads to making new social capital.

The third interesting program is a collaboration between two generations of cooks in a local Japanese restaurant, a father and daughter, who have a strong attachment to local foodstuff and the local farmers who provide local farm produce. The cooks offer a cooking class on Japanese cuisine based on the local foodstuff. The fourth program evokes the richness of the local food heritage from a longer historical perspective. That is a restoration of cuisine from the Edo period, which is the longest and last samurai period before the modernization began. This program was originally based on a recipe book found in the old warehouse of an old feudal family published 150 years ago. This program is collaboration with the local Chamber of Commerce, farmers and another NPO.

To summarize. KTN puts an emphasis on presenting holistic experience programs on the local food heritage, which connects local people and enables them to preserve the food heritage.

\subsubsection{Agrarian heritage experience programs}

The first farm operation experience is a lotus roots operation program. Lotus roots are a traditional local farm product grown in this area, and the KTN created a program that enables participants to experience the process of an entire growing season for this produce; planting, weeding, harvesting and studying the local food heritage. Such a program covering an entire growing season is not common because harvesting and/or planting are the most common 
experiences offered because they are symbolic operations. The KTN thinks that it is important to let participants know the authentic complete process of a farm operation rather than presenting a fragmentary program only presenting the popular parts of a farm operation.

The second farm operation is conic piling of rice straw in an organic paddy. This farm operation has been conducted after the rice harvest to dry the harvested rice by natural ventilation. Rice dried in this manner has a better taste than artificially dried rice. After the mechanization, however, this old rice drying method is dying out due to its labour-intensive nature, as it must be done manually. So, this program aims to preserve dying skills in traditional farm operations by creating a chance for visitors to learn these skills. This program also provides a chance for local persons who have such skills to teach, which enables dying skills to be kept alive.

Such policy is also reflected in the program of rice-straw craft, making "simenawa", which is a woven rice-straw rope. Making "simenawa" has been an agrarian custom for farmers in the slack winter season in preparations for the New Year celebration and worship of deities and ancestors. The rice-straw craft has been used to make sacred ornaments for these ceremonial events to keep away bad luck. With this program, the KTN tries to recover and hand over this tradition to the next generation. For this purpose, the KTN used a small paddy that had been abandoned for more than a decade. Participants grew rice in this paddy starting from planting to harvest. The final product here is not rice, but green rice straw. Thus, rice is harvested earlier than usual so that the straw remains green. These organized programs are implemented with a small unit of people and in short periods of around two hours to have a compact and efficient program.

To summarize, the KTN pays attention to provide a holistic process of traditional farm production keeping in mind effective and efficient program management.

\section{DISCUSSION}

Now let me discuss the role of this NPO and the effect generated to the local community as shown in Fig. 2. The roles of KTN are shown in the left column and the effects in the right side. The four main roles are listed as connecting people-to-people within the community, helping each other, looking back to one's heritage, and finding roles that suit one's self. On the right, the four main effects are listed: creating small income opportunities, raising selfconfidence of local participants, sharing and forming clear local identity and maximizing satisfaction of local people.

Finally, KTN faces challenges from three aspects. The first is program management, the second is financial issues and the third is exploration of new markets such as the attraction of inbound tourists from abroad. As to program management, the KTN has created many programs and now thinks that the number of programs that it handles has exceeded what would be appropriate considering the limited number of staff members. It is necessary to streamline the number of programs for more efficient program management. On the financial issue, financial stability is crucial for the sustainability of this organization, which is a common issue for every NPO. To increase financial stability, the KTN will start to provide an accommodation service by acquiring an old farmhouse, which is now rented by its owner to be used as the KTN office. This point is related to the third point.

To explore new markets for the tourism business, growing attention is now paid to tourists from abroad in every part of this country. This is because Japan has been experiencing a sharp and straight increase in the number of inbound tourists from abroad since 2012; 8.61 million in 2012 to 28.69 million in 2017 due to the government inbound tourism promotion policy. Of course, although tourists from Asia account for the majority, the number of tourists from 

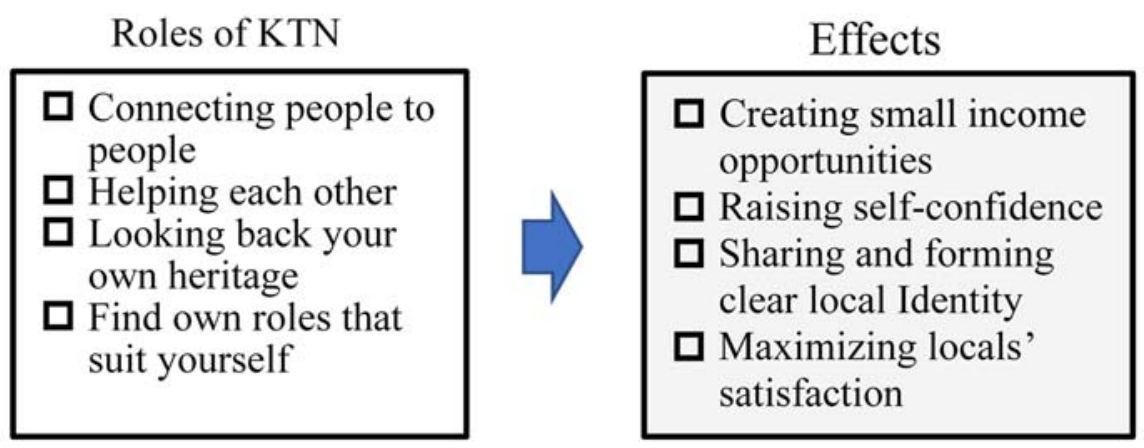

Figure 2: Effects on local community through KTN programs.

the rest of the world has also increased, such as from North and South America, Europe and Oceania. Nevertheless, the Tohoku region, including Miyagi, is not well recognized yet despite its huge potential as a tourist destination for foreigners. Therefore, how to attract tourists from abroad is a common issue for rural areas in this country, including the aspect of language skills. To explore the inbound market, it is necessary to establish a promotion strategy from middle and long-term perspectives.

\section{CONCLUSION}

This paper investigated the role played by NPOs on CBT development through a case study by focussing on the KTN in Miyagi, northern Japan. Main findings are as follows:

1) The author classified CBT into three types depending on the range of the local community; the single hamlet level, the single municipality level and the level of multiple municipalities. The KTN focus was a type that connects people over multiple municipalities although these municipalities have been merged into a single one.

2) The studied NPO, i.e. the KTN, connects local residents through rural experience programs by taking advantage of the rural and food heritage from previous generations in the agrarian community. The KTN shows respect by offering programs in living heritage practiced by local people in ordinary life, which is essential for authentic program-making, the establishment of self-confidence and rediscovery of the local identity, but is often forgotten in busy modern life.

3) Based on this principle, KTN built a system to provide opportunities for local people to earn small incomes without imposing a heavy burden. Those individuals are involved as instructors and other role players such as providers of local foodstuff and related craft makers.

4) The unique way of program implementation is that the KTN is not oriented toward mass tourism, but provides programs with a small number of participants within short time duration to guarantee authenticity. Another feature is a holistic approach to give participants an opportunity to experience the whole process of farm production and craft making.

5) Finally, to counter the current issues of program management, financial viability and the exploration of new markets, this NPO needs to make a balance between efficient operation of programs and maintaining its authentic/holistic nature. Partnership with experts such as those who have skills in English and ICT from outside of the local community will increase its importance. 


\section{ACKNOWLEDGEMENTS}

The author is grateful for the Tohoku Regional Advancement Center and the Kurihara Tourism Network for the implementation of the survey of this study. This study was partly financed by Grants-in Aid for Scientific Research No. 26283017, Japan Society for the Promotion of Science (JSPS).

\section{REFERENCES}

[1] Hatton, M.J., Community-based Tourism in the Asia-Pacific, Toronto: APEC Publication, 1999.

[2] Manhas, P.S., Gupta, D.R. \& Gupta, A., Strategic Development Policies and Impact Studies of Sustainable Rural and Community-based Tourism, Delhi: Primus Books, 2014.

[3] Dittmann, M., Community Based Tourism: Modern Destination Management, Saarbrücken: VDM Verlag, 2009.

[4] Burgos, A. \& Mertens, F., Participatory management of community- based tourism: a network perspective, Community Development, 48(4), pp. 546-565, 2017.

[5] Masud, M.M., Aldakhil, A.M., Nassani, A.A. \& Azam, M.N., Community-based ecotourism management for sustainable development of marine protected areas in Malaysia. Ocean \& Coastal Management, 136, pp. 104-112, 2017.

[6] Ernawati, N.M., Sanders, D. \& Dowling, R., Host-guest orientations of communitybased tourism products: a case study in Bali, Indonesia. International Journal of Tourism Research, 19, pp. 367-382, 2016.

[7] Harmini, A.A.A.N. \& Sadguna, I.G.A.J., Community based tourism management at Pinge village, Tabanan Regency, Bali, European Journal of Sustainable Development, 6(4), pp. 497-501, 2017.

[8] Durkin, J. \& Perić, M., Organising for community-based tourism: comparing attitudes of local residents and local tourism entrepreneurs in Ravna Gora, Croatia. Local Economy, 32(7), pp. 678-691, 2017.

[9] Giampiccoli, A. \& Mtapuri, O., Beyond community-based tourism. Towards a new tourism sector classification system. Gazeta de Antropologia, 33(1), pp. 1-14, 2017. http://hdl.handle.net/10481/44467. Accessed on: 19 Jan. 2018.

[10] Ohe, Y. \& Kurihara, S., Evaluating the complementary relationship between local brand farm products and rural tourism: Evidence from Japan. Tourism Management, 35, pp. 278-283, 2011.

[11] Ohe, Y. Ikei, H, Chorong, S. \& Miyazaki, Y., Evaluating the relaxation effects of emerging forest-therapy tourism: a multidisciplinary approach. Tourism Management, 62, pp. 322-334, 2017.

[12] Cai, L.A., Gartner, W.C. \& Munar, A.M., Bridging Tourism Theory and Practice Volume 1, Tourism Branding: Communities in Action, Wagon Lane: Emerald, 2009.

[13] Kim, K.H. \& Park, D.B., Relationships among perceived value, satisfaction, and loyalty: community-based ecotourism in Korea. Journal of Travel \& Tourism Marketing, 34(2), pp. 171-191, 2017.

[14] Ohe, Y., Community-based rural tourism in super-ageing Japan: challenges and evolution. Anais Brasileiros de Estudos Turísticos - ABET, 6(1), pp. 28-41, 2016.

[15] Ohe, Y., Roles of network-integrating NPOs that connects local stakeholders in rural tourism: evidence from Japan. Tourism and Leisure: Current Issues and Perspectives of Development, eds H. Pechlaner \& E. Smeral, Springer Gabler, pp. 231-244, 2014.

[16] Coleman, J.S., Social capital in the creation of human capital. American Journal of Sociology, 94, pp S95-S120, 1988. 
[17] Burt, R.S., Structural holes versus network closure as social capital. Social Capital: Theory and Research, eds N. Lin, K. Cook \& R.S. Burt, Transaction Publishers: New Brunswick, pp 31-56, 2001.

[18] Ohe, Y., Characterizing rural tourism in Japan: features and challenges. Cultural Tourism, eds P. Diaz \& M.F. Schmitz, WIT Press: Southampton, pp. 63-75, 2014.

[19] Cabinet Office, Annual Report on the Aging Society: 2016 (Summary). www8.cao.go.jp/kourei/english/annualreport/2016/2016pdf_e.html. Accessed on: 15 Jan. 2018. 